\title{
Efecto de la temperatura y salinidad del agua en la incubación de huevos de botete diana Sphoeroides annulatus
}

Effects of temperature and salinity on the egg incubation of bullseye puffer fish Sphoeroides annulatus

\section{Ma. Isabel Abdo-de la Parra1, Irma E. Martínez-Rodríguez', Blanca González-Rodríguez', L. Estela Rodríguez-Ibarra ${ }^{1}$, Neil Duncan ${ }^{2}$ y Crisantema Hernández ${ }^{1}$}

\begin{abstract}
${ }^{1}$ Centro de Investigación en Alimentación y Desarrollo A.C, Unidad Mazatlán, Av. Sábalo Cerritos s/n, C.P. 82100 Mazatlán, Sinaloa, México.abdo@ciad.mx

${ }^{2}$ IRTA, Aquaculture Centre, Institut d' Recerca i Tecnologia Agroalimentàries, 43540 Saint Carles de la Rapita, Tarragona, España
\end{abstract}

\begin{abstract}
The effects of different water temperatures (22, 25, 28 and $\left.31^{\circ} \mathrm{C}\right)$ and salinities between 0 and 60 psu (with intervals of $5 \mathrm{psu}$ ) on egg incubation of the bullseye puffer (Sphoeroides annulatus) were evaluated in this study. The embryos could not develop at $22^{\circ} \mathrm{C}$ and the highest hatching rate for normal larvae was observed at $28^{\circ} \mathrm{C}$. At $0,50,55$ and 60 psu larvae were unable to develop. Highest hatching rates were obtained at 25,30 and $35 \mathrm{psu}$. It was concluded that water temperature and salinity affects the incubation period, embryo development stage and larval survival of the bullseye puffer.
\end{abstract}

Key words: Embryo development, period incubation, hatch, deformed larvae

\section{INTRODUCCIÓN}

La temperatura y la salinidad del agua son dos de los principales factores que influyen en los procesos vitales de los peces; por ejemplo, la temperatura controla el tiempo de incubación de los huevos y la supervivencia de embriones y larvas, para lo cual, cada especie requiere de un rango óptimo de temperatura para su desarrollo; cuando los huevos son incubados fuera de este intervalo, el desarrollo embrionario puede acelerarse o retardarse, produciendo embriones y larvas deformes, bajos porcentajes de eclosión y elevada mortalidad de larvas eclosionadas (e.g., Berlinsky et al. 2004, Anguis \& Cañavate 2005, Radoniæ et al. 2005, Yang \& Chen 2005, Geffen et al. 2006, Jordaan et al. 2006, Shi et al. 2010).

A su vez la salinidad también es un factor importante para la incubación de huevos de peces, ya que fuera de un rango óptimo de salinidad, el desarrollo embrionario se ve afectado, provocando malformaciones en embriones y larvas, puede alargar el tiempo y disminuir el porcentaje de eclosión (Smith et al. 1999, Haddy \& Pankhurst 2000, Kucera et al. 2002, Hennea \& Watanabe 2003, Jian et al. 2003, Berlisnky et al. 2004, Gracia-López et al. 2004, Zhang et al. 2010). El botete diana, Sphoeroides annulatus (Jenyns, 1842) es un pez marino con un alto valor comercial en el mercado mexicano y actualmente está considerado como una de las principales especies para la diversificación de la maricultura en México. Aunque ya se desarrolló la técnica para la inducción a la maduración (Duncan et al. 2003, Abdo-de la Parra et al. 2010), existe poca información acerca de las condiciones óptimas para el desarrollo embrionario del botete diana como el trabajo realizado por Komar et al. (2004) relacionado con la aireación y filtración del agua de incubación y los trabajos reportados por Rodríguez-Ibarra et al. $(2010,2011)$ relacionados con el desgomado y tratamientos profilácticos de los huevos de botete diana, respectivamente. Sin embargo, no hay reportes sobre el efecto de la temperatura y salinidad del agua de incubación de los huevos de esta especie. Un paso esencial para el éxito del cultivo de cualquier especie, es determinar las condiciones físico-ambientales óptimas para la incubación de huevos. 
La determinación del rango de temperatura y salinidad adecuado para la incubación de huevos de botete diana es esencial para maximizar la producción de semilla de laboratorio, lo cual hace sustentable a cualquier cultivo de organismos acuáticos. Por lo tanto, el objetivo del presente trabajo fue determinar los intervalos adecuados de temperatura y salinidad del agua de incubación para el óptimo desarrollo embrionario, eclosión y supervivencia de larvas del botete diana, para contribuir al desarrollo de la tecnología de cultivo de esta importante especie.

\section{Materiales Y MÉtodos}

\section{REPRODUCTORES}

Los reproductores se capturaron artesanalmente por medio de anzuelos, en la boca del estero de Teacapán, Sinaloa y se transportaron a las instalaciones de investigación del Centro de Investigación en Alimentación y Desarrollo, A.C. (CIAD) Unidad Mazatlán, donde se colocaron en estanques circulares negros de fibra de vidrio con capacidad de $3 \mathrm{~m}^{3}$ provistos con sistemas de flujo continuo ( 4 volúmenes día ${ }^{-1}$ ) de agua de mar filtrada por filtros de arena y de cartucho de $5 \mu \mathrm{m}$ de retención y con aireación. Durante la primera semana se les alimentó con alimento fresco (pescado, calamar y camarones) el cual, posteriormente se sustituyó por alimento balanceado para reproductores de trucha (El Pedregal, Silver Cup, Toluca, México) y una dieta elaborada en CIAD basada en Kanazawa (1991). Para la inducción a la maduración final, se seleccionaron hembras de alrededor de $800 \pm 50$ $\mathrm{g}$ y $30 \pm 5 \mathrm{~cm}$ de longitud total (LT) que presentaron oocitos con un diámetro mayor a $0,5 \mathrm{~mm}$ y se les aplicaron dos inyecciones de Des-Gly ${ }^{10}$, [D-Ala $\left.{ }^{6}\right]$-Luteinizing hormone-releasing hormone ethylamide (LHRHa) (día 0: $20 \mu \mathrm{g} \mathrm{kg}^{-1}$ de peso de la hembra, y el día 2: $40 \mu \mathrm{g} \mathrm{kg}^{-1}$ ). Las hembras ovularon al tercer día después de las inyecciones (Duncan et al. 2003). Las hembras inducidas se separaron del resto del lote de reproductores en otro estanque con las mismas características ya descritas. Se seleccionaron machos maduros naturalmente, con un peso promedio de $750 \pm 20$ g y $28 \pm 1,5 \mathrm{~cm}$ de LT.

\section{OBTENCIÓN Y FERTILIZACIÓN DE HUEVOS}

La fertilización se realizó artificialmente, ambos gametos se extrajeron por presión abdominal y se mezclaron durante 2 min con agua marina filtrada y esterilizada con UV. Los huevos fertilizados se enjuagaron con agua esterilizada para eliminar el exceso de esperma e impurezas (Duncan \& Abdo-de la Parra 2002, Abdo-de la Parra et al. 2010).

\section{SISTEMA EXPERIMENTAL PARA LA INCUBACIÓN DE HUEVOS}

Se montó un sistema cerrado de incubación de huevos en 5 cajas de plástico (Mik Pirámide ${ }^{\circledR}$, mod. 551) que contenían $30 \mathrm{~L}$ de agua dulce mantenida a la temperatura requerida para cada tratamiento; sobre las cajas se colocó un soporte horizontal con perforaciones para soportar recipientes de plástico de $300 \mathrm{~mL}$. Las temperaturas experimentales se controlaron por medio de termostatos $\left(\right.$ Termal $\left.{ }^{\circledR}, 300 \mathrm{~W}\right)$, los cuales se colocaron dentro de las cajas de plástico. El sistema se montó en un cuarto climatizado para mantener la temperatura del agua a $22^{\circ} \mathrm{C}$ y a partir de esta temperatura se regularon los termostatos para alcanzar las temperaturas evaluadas.

\section{EFECTO DE LA TEMPERATURA EN LA INCUBACIÓN DE HUEVOS}

Los huevos del botete diana son adherentes por lo que se adhirieron 50 huevos fertilizados en portaobjetos, los cuales se colocaron en los recipientes de incubación con $250 \mathrm{~mL}$ de agua de mar a 35 ups, filtrada con UV. Las temperaturas de incubación fueron $22 \pm 0,2 ; 25 \pm 0,3 ; 28 \pm$ 0,2 y $31 \pm 0,1^{\circ} \mathrm{C}$; con cinco réplicas por cada tratamiento. A las 24, 48, 72 y 96 h post-fertilización (HPF) se observaron las laminillas para contar huevos muertos, eclosionados y número de larvas presentes por medio de un microscopio estereoscópico Estereomaster ${ }^{\circledR}$ (Fisher Inc., USA) con una magnificación de 100x. Las larvas eclosionadas al momento de cada observación se extrajeron de los recipientes para no ser contadas nuevamente. Se tomaron fotografías de los huevos de cada tratamiento al momento de cada conteo y de las larvas eclosionadas en un microscopio compuesto (Zeiss ${ }^{\circledR}$, Axioskop 20) con una cámara digital integrada (MC 80) y magnificación de 50x, para observar el desarrollo embrionario y la eclosión.

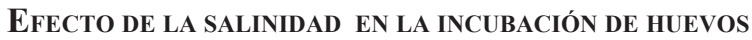

El sistema de incubación utilizado fue el mismo que para el bioensayo de temperatura. En este caso la temperatura se mantuvo constante a $28 \pm 0,1^{\circ} \mathrm{C}$, en un portaobjetos se colocaron 50 huevos fertilizados de botete diana y cada uno se colocó en los recipientes de incubación con 250 $\mathrm{mL}$ de agua de mar con las 13 salinidades diferentes, desde 0 a 60 ups a intervalos de 5 ups, con 5 réplicas en cada tratamiento. Para ajustar las salinidades menores a 35 ups se realizaron diluciones con agua dulce y para las salinidades mayores se agregó cloruro de sodio (JT Baker, USA); diariamente se registró la salinidad con un refractómetro para observar si aumentaba por la evaporación del agua y en ese caso se agregaba agua dulce para regularla. A las 24, 48, 72 y 96 HPF se observó 
el desarrollo embrionario y se contó el número de larvas y huevos muertos en el microscopio estereoscópico. Los huevos de cada tratamiento y de las larvas eclosionadas fueron registradas fotográficamente. Los porcentajes de eclosión de ambos experimentos se calcularon mediante la siguiente fórmula (Ottesen \& Bolla 1998): \% de eclosión $=\mathrm{N}^{\mathrm{o}}$ de larvas eclosionadas $/ \mathrm{N}^{\circ}$ total de huevos incubados $\mathrm{x} 100$.

\section{Análisis estadísticos}

Los datos de porcentaje de eclosión se transformaron a arcoseno (Zar 1999) y se determinó la normalidad de su distribución (prueba de Bartlet) y la homocedasticidad de su varianza (prueba de Levene) y se aplicó un ANDEVA $(P<0,05)$. Para determinar las medias significativamente diferentes entre niveles de factores se aplicaron pruebas de comparaciones múltiples de Tukey. Se utilizó el programa estadístico Statgraphics Software Versión 5 (STSC Inc., Rockville Maryland, USA).

\section{RESULTAdOS Y DISCUSIÓN}

\section{EFECTO DE LA TEMPERATURA EN LA INCUBACIÓN DE HUEVOS}

Los huevos vivos fertilizados de botete diana son esféricos, con un diámetro de 0,7 $\pm 0,03 \mathrm{~mm}$, son demersales, adherentes y transparentes. En huevos vivos de 50 HPF el vitelo contiene un aglomerado de glóbulos de aceite y la formación del embrión (Fig. 1a); en cambio los huevos muertos presentaron un color obscuro y opaco (Fig. 1b). A las 24 HPF los huevos incubados a $22^{\circ} \mathrm{C}$ no continuaron desarrollándose y se presentó el $100 \%$ de mortalidad. Los embriones del resto de los tratamientos continuaron su desarrollo. A las 48 HPF inició la eclosión a $31^{\circ} \mathrm{C}$; sin embargo, las larvas eclosionadas presentaron anormalidades y en el resto de los tratamientos, la eclosión se inició a las 72 HPF y finalizó en los tres tratamientos a las $96 \mathrm{HPF}$. Los porcentajes de eclosión a las $96 \mathrm{HPF}$ a $28^{\circ} \mathrm{C}$ y a $31^{\circ} \mathrm{C}$ (alrededor de $60 \%$ ) fueron significativamente diferentes $\left(\mathrm{F}_{(2,14)}=34,45, P<0,01\right)$ al porcentaje de eclosión

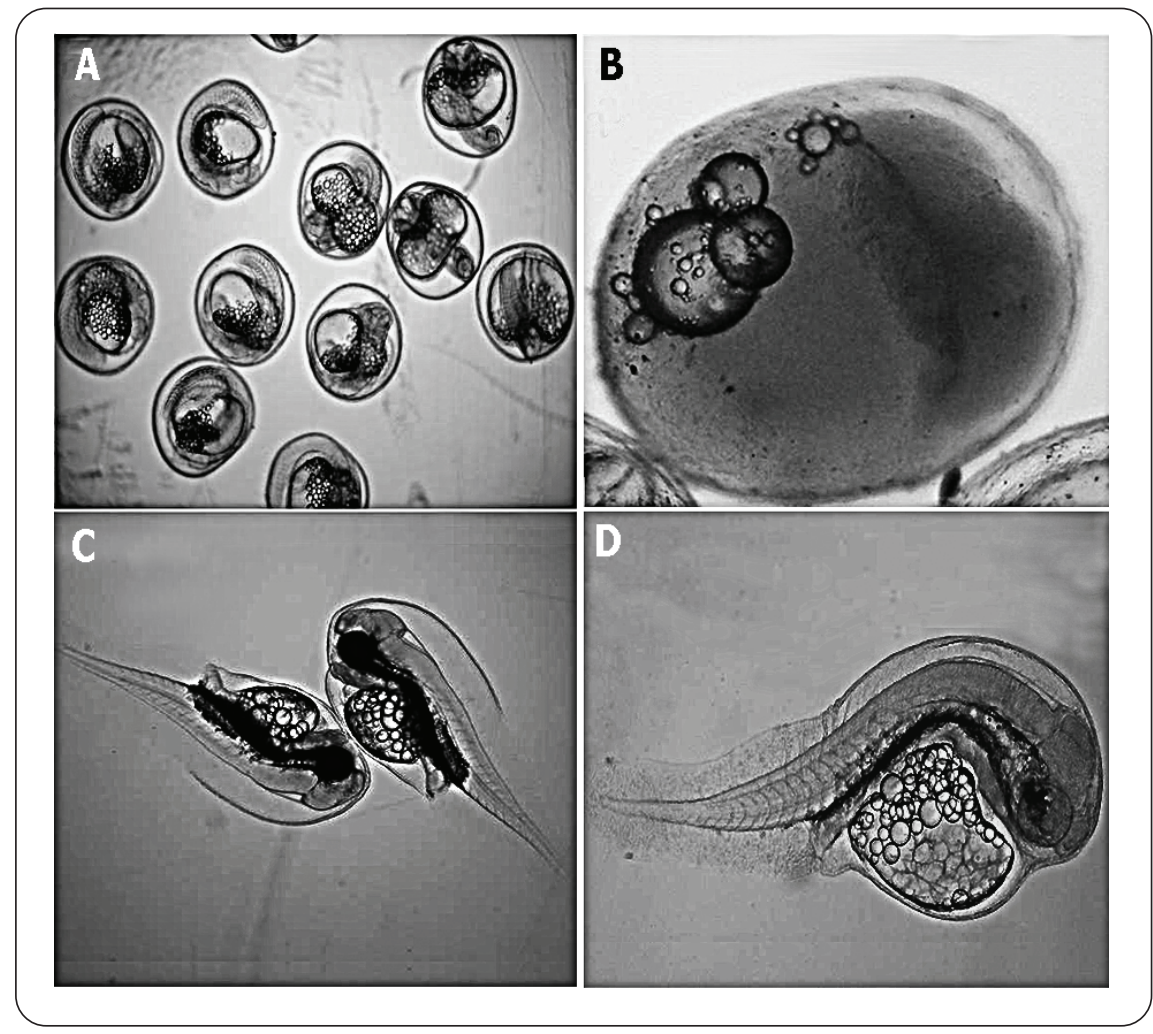

Figura 1. Huevos fertilizados y larvas de botete diana S. annulatus: a) huevos vivos, b) huevos muertos a las $50 \mathrm{HPF}$ y $22^{\circ} \mathrm{C}$, c) larva normal $(2,0 \pm 0,2 \mathrm{~mm}$ de $\mathrm{LT})$ a $28^{\circ} \mathrm{C}$, d) larva deforme $\left(1,4 \pm 0,3 \mathrm{~mm}\right.$ de LT) eclosionada a las $48 \mathrm{HPF}$ a $31^{\circ} \mathrm{C} / \mathrm{Eggs}$ and larvae of bullseye puffer S. annulatus: a) live fertilized eggs, b) dead fertilized egg at $50 \mathrm{HPF}$ and $22^{\circ} \mathrm{C}, \mathrm{c}$ ) normal larvae $(2.0 \pm 0.2 \mathrm{~mm} \mathrm{TL})\left(28^{\circ} \mathrm{C}\right)$, d) deformed larvae $(1.4 \pm 0.3 \mathrm{~mm} \mathrm{TL})$ hatched at $48 \mathrm{HPF}$ at $31^{\circ} \mathrm{C}$ 
(20\%) obtenido a $25^{\circ} \mathrm{C}$ (Fig. 2). A este tiempo de incubación no se presentaron larvas deformes en ninguno de los tratamientos. Estos resultados sugieren que la incubación de huevos de esta especie debe realizarse a temperaturas mayores a $25^{\circ} \mathrm{C}$. Se ha demostrado que los estadios tempranos de los huevos de peces antes de que el embrión esté completamente formado, son muy sensibles a los cambios del medio ambiente, tales como la temperatura y el oxígeno disuelto (Stickney 2000); como por ejemplo, en otras especies de botete como Takifugu obscurus (Yang \& Chen 2005) y T. flavidus (Shi et al. 2010), así como para otros peces marinos tales como Sprattus sprattus (Petereit et al. 2008), Centropristis striata (Berlinski et al. 2004), Mycteroperca rosacea (Gracia-López et al. 2004), entre otras. Por otro lado, al incubar los huevos de botete diana a $31^{\circ} \mathrm{C}$, se aceleró el desarrollo embrionario y la eclosión se inició a las 48 HPF; sin embargo, las larvas eclosionadas, a este tiempo, presentaron los ojos sin pigmentación y el notocordo encorvado (Fig. 1d). Se ha reportado para muchas especies de peces que al incrementar la temperatura de incubación más allá del rango óptimo de cada especie, se acelera el desarrollo embrionario y se acorta el tiempo de eclosión; sin embargo, puede provocar anormalidades en las larvas eclosionadas e incrementar la mortalidad (Hansel \& Falk-Petersen 2001, Rutaisire \& Booth 2004, Cingi et al. 2010, Shi et al. 2010). En este estudio, aunque no fue calculado, se observó que el aglomerado de los glóbulos de aceite del vitelo era más pequeño en los huevos incubados a $31^{\circ} \mathrm{C}$. Tucker (1998) mencionó que cuando la temperatura es mayor a la óptima, existe una tendencia de que el vitelo se agote rápidamente y las larvas eclosionan prematuramente, provocando que las larvas tengan reservas energéticas deficientes y poca habilidad para alimentarse, incrementando la mortalidad. A $28^{\circ} \mathrm{C}$ la eclosión se inició a las 72 HPF y las larvas no presentaron deformidades (Fig. 1c); este tiempo de eclosión es el reportado para esta especie en estudios anteriores, a temperaturas entre 27 a $28,5^{\circ} \mathrm{C}$ y con los mismos porcentajes de eclosión final, alrededor de $60 \%$ (Abdo-de la Parra et al. 2001, García-Ortega et al. 2003, Abdo-de la Parra et al. 2010). En Abdo-de la Parra et al. (2010) se reportó que a $24,5^{\circ} \mathrm{C}$ la eclosión se inició hasta las 96 HPF. En el presente estudio la eclosión finalizó en todos los tratamientos a las 96 HPF y aunque el porcentaje de eclosión final no fue estadísticamente significativo a este tiempo entre los huevos incubados a 28 y a $31^{\circ} \mathrm{C}$, el total de larvas viables no es igual, ya que las que eclosionaron prematuramente estaban deformes. El rango óptimo de temperatura para la incubación de huevos de cada especie en particular, dependerá de sus características biológicas y ecológicas (Tucker 1998); y en este sentido, el mayor pico de reproducción del botete diana en la costas de Sinaloa se ha reportado para los meses de abril y mayo y un pico menor en los meses de octubre y noviembre (Sánchez-Cárdenas et al. 2007), temporada en la cual, la temperatura del mar oscila entre 26 y $28^{\circ} \mathrm{C}$. Los resultados de este estudio mostraron que la temperatura del agua de incubación tiene un efecto sobre el desarrollo embrionario, tiempo y porcentaje de eclosión de las larvas de botete diana.

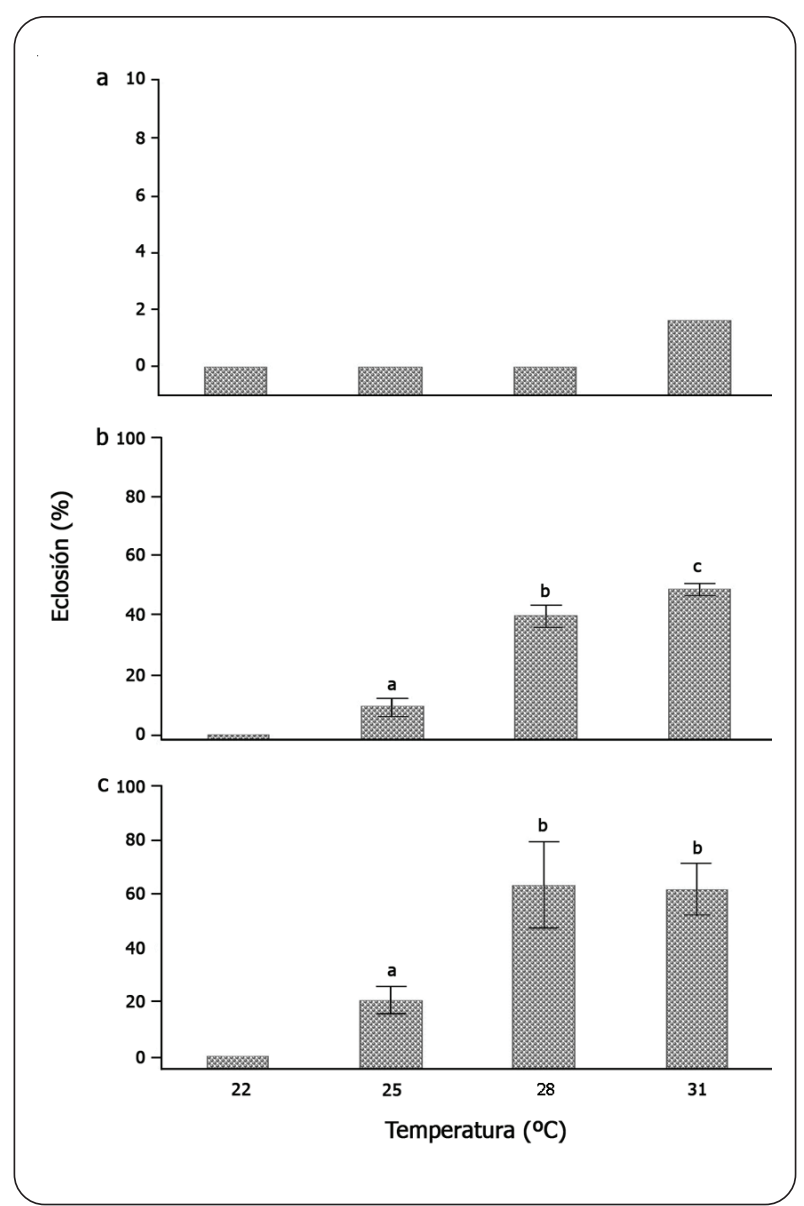

Figura 2. Porcentajes de eclosión (medias \pm desviación estándar, $\mathrm{n}=5$ réplicas) de huevos de botete diana $S$. annulatus incubados a diferentes temperaturas: a) $48 \mathrm{HPF}$, b) $72 \mathrm{HPF}$ y c) $96 \mathrm{HPF}$. Letras diferentes en la barra indican diferencia significativa entre tratamientos $(P<0,05)$. HPF $=$ Horas post-fertilización / Hatching percentage (mean \pm S.E., $n=5$ replicates) of bullseye puffer S. annulatus embryos incubated at different temperatures: a) 48 HPF; b) 72 HPF y c) 96 HPF. Different letters in the bar indicate significant difference among treatments $(P<0.05)$. HPF $=$ Hours after fertilization 


\section{EFECTO DE LA SALINIDAD EN LA INCUBACIÓN DE HUEVOS}

Se determinó que la salinidad también afectó significativamente el desarrollo embrionario y porcentaje de eclosión de las larvas del botete diana. A 0, 55 y 60 ups el embrión empezó a desarrollarse, pero aproximadamente a las $12 \mathrm{HPF}$ cesó la división celular y a las $24 \mathrm{HPF}$ se presentó el $100 \%$ de mortalidad en estos tratamientos. En el resto de los tratamientos el desarrollo embrionario continuó y no se observó eclosión. A las 72 HPF se inició la eclosión en todos los tratamientos restantes (Fig. 3); sin embargo, las larvas eclosionadas en 5 ups no sobrevivieron al entrar en contacto con el medio y en lo huevos no eclosionados, se detuvo el desarrollo. A 10 y 45 ups las larvas eclosionadas si sobrevivieron al entrar en contacto con el agua, aunque el porcentaje de eclosión fue mínimo (6 y $15 \%$, respectivamente). Ottesen \& Bolla (1988) reportaron que las larvas recién eclosionadas de Hippoglossus hippoglossus no sobrevivían al entrar en contacto con agua a salinidades menores a 10 ups; este mismo efecto fue reportado por Smith et al. (1999) para Paralichthys lethogstima. Según Riis-Vestergaard (1987) (fide Kucera et al. 2002) los huevos fertilizados de los peces son impermeables a los solutos y son capaces de mantener su osmolalidad a diferentes gradientes de salinidad; sin embargo el proceso de eclosión es afectado por los valores extremos de salinidad (Kucera et al. 2002), como se observó en el presente estudio, y esto se debe principalmente a que las larvas recién eclosionadas no tienen completamente las branquias, los intestinos y riñones formados, por lo que tampoco son funcionales; por lo tanto, no cuentan con las capacidades osmorreguladoras de los adultos. Sin embargo, las larvas son capaces de tolerar un amplio rango de salinidades debido a su piel relativamente impermeable y a sus células de cloro cutáneas (Kucera et al. 2002), posiblemente por eso, las larvas que eclosionaron en el presente estudio a 10 y 45 ups fueron capaces de sobrevivir al entrar en contacto con el agua.

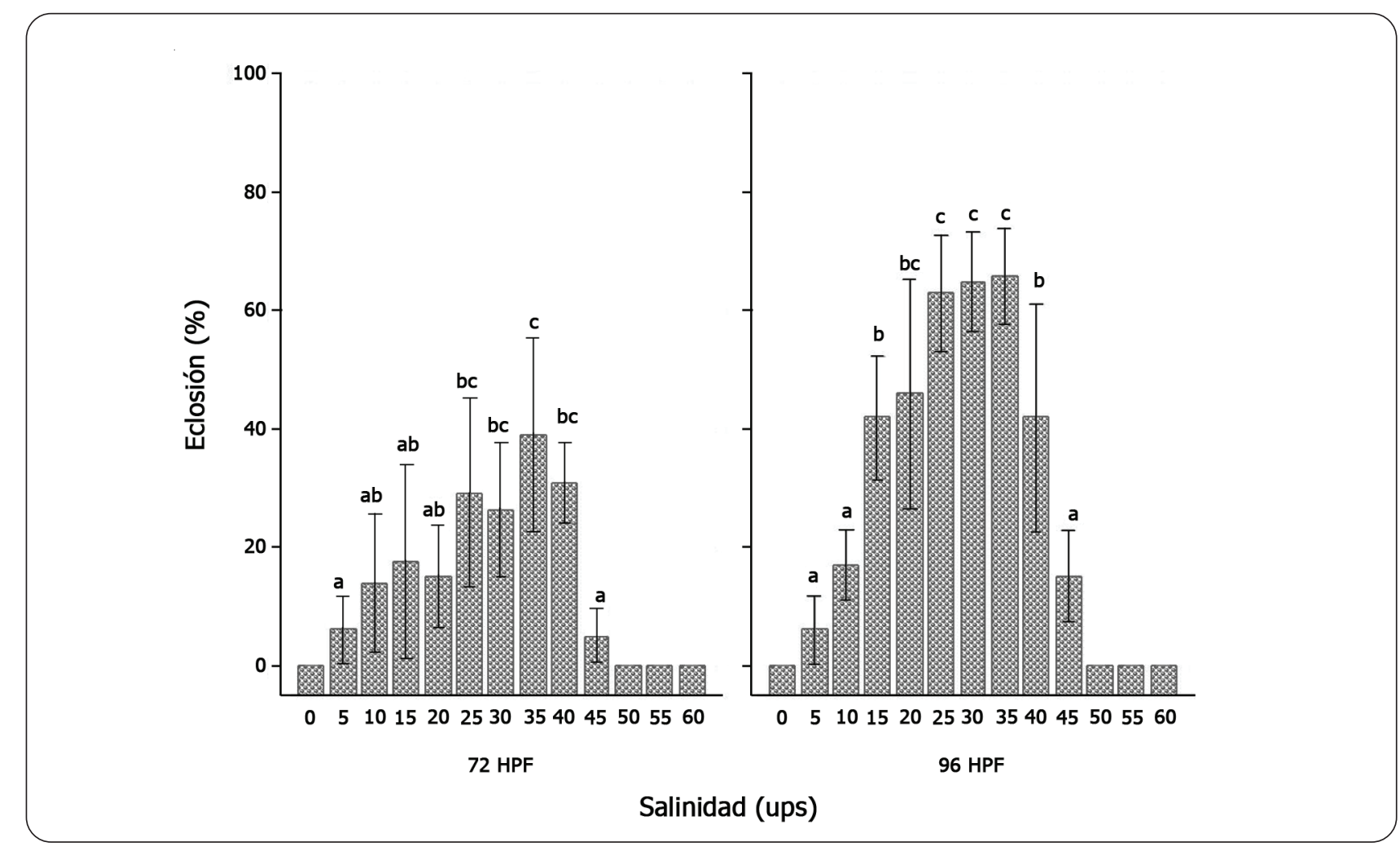

Figura 3. Porcentajes de eclosión (medias \pm D.E., $n=5$ réplicas) de huevos de botete diana $S$. annulatus incubados a diferente salinidad. Letras diferentes en la barra indican diferencia significativa entre tratamientos $(P<0,05)$. HPF $=$ Horas post-fertilización / Hatching percentage (mean \pm S.D. $n=5$ replicates) of bullseye puffer $S$. annulatus embryos incubated at different salinities. Different letters in the bar indicate significant difference among treatments $(P<0.05)$. HPF $=$ Hours after fertilization 
A las 96 HPF se completó la eclosión en todos los tratamientos; a 10 y 45 ups el porcentaje de eclosión no fue mayor de $18 \%$; a 15,20 y 40 ups eclosionó solo alrededor del $40 \%$; a 25,30 y 35 ups se presentaron los mayores porcentajes de eclosión $(65 \%)$, siendo significativamente diferentes $\left(\mathrm{F}_{(8,44)}=15,32, P<0,0001\right)$ al resto de los tratamientos (Fig. 3). No se observaron larvas deformes en algún tratamiento.

Los peces que se distribuyen en aguas costeras, usualmente son eurihalinos, cuyos embriones y larvas pueden tolerar un amplio rango de salinidad (Tucker 1998); tal es el caso del botete diana que se distribuye en las costas de San Diego, California hasta Perú y penetra también en lagunas costeras (Thompson et al. 1987). En el presente estudio se demostró que los embriones de esta especie pueden desarrollarse y las larvas eclosionar en salinidades desde 15 a 40 ups. Resultados similares se han reportado para otras especies de distribución costera como es el caso de Mycteroperca rosacea (Gracia-López et al. 2004), Acanthopagrus butcheri (Haddy \& Pankhurst, 2000) y Takifugu flavidus (Zhang et al. 2010), entre otras. Los mayores porcentajes de eclosión de larvas de botete diana se presentaron en los tratamientos de 25,30 y 35 ups, estos valores coinciden con los valores de salinidad en los cuales se lleva a cabo la época de reproducción natural reportada para esta especie en las costas de Sinaloa, México (Sánchez-Cárdenas et al. 2007).

El presente estudio ha demostrado que el desarrollo embrionario y el tiempo de eclosión de las larvas de botete diana dependen de la temperatura de incubación, y los huevos pueden incubarse a salinidades desde 15 a 40 ups sin efectos adversos, lo que sugiere que esta especie de pez es eurihalina.

\section{Agradecimientos}

Los autores agradecen a V. Williams de Calvario por la traducción del resumen y revisión del texto y la asistencia técnica de F. Hernández-Peinado. Este trabajo fue financiado por el proyecto CONACYT J28342B dirigido por N. Duncan.

\section{LITERATURA CITADA}

Abdo-de la Parra I, A García-Ortega, I Martínez-Rodríguez, B González-Rodríguez, G Velasco, C Hernández \& NJ Duncan. 2001. Larval rearing of the mexican bullseye puffer (Sphoeroides annulatus) under hatchery conditions. En: Hendry CI, G Van Stappen, M Wille \& P Sorgeloos (eds). $3^{\text {rd }}$ Fish and Shellfish larviculture Symposium, pp. 4-7. Ghent University, Belgum.
Abdo-de la Parra MI, A García-Ortega, I MartínezRodríguez, B González-Rodríguez, G Velasco-Blanco, C Hernández \& N Duncan. 2010. An intensive hatchery rearing protocol for larvae of the bullseye puffer, Sphoeroides annulatus (Jenyns). Aquaculture Research 41(10): e554-e560.

Anguis V \& JP Cañavate. 2005. Spawning of captive Senegal sole (Solea senegalensis) under a naturally fluctuating temperature regime. Aquaculture 243(3): 133-145.

Berlinsky D, J Taylor, R Howell, T Bradley \& TI Smith. 2004. The effects of temperature and salinity on early life stages of black sea blass (Centropristis striata). Journal of the World Aquaculture Society 35(3): 335-344.

Cingi S, M Keinanen \& PJ Vuorinen. 2010. Elevated water temperature impairs fertilization and embryonic development of whitefish Coregonus lavaretus. Journal of Fish Biology 76: 502-521.

Duncan N \& I Abdo-de la Parra. 2002. Marine fish specialists focus on puffer fish. World Aquaculture 33(3): 34-38.

Duncan NJ, N García-Aguilar, G de Rodríguez-M, M Bernardet, C Martínez-Chávez, C Komar, P Estañol \& A García-Gasca. 2003. Reproductive biology of captive bullseye buffer (Sphoeroides annulatus), LHRHa induced spawning and egg quality. Fish Physiology Biochemistry 28: 505-506.

García-Ortega A, I Abdo-de la Parra \& C Hernández. 2003. Weaning of bullseye puffer (Sphoeroides annulatus) from live food to microparticulate diets made with decapsulated cysts of Artemia and fishmeal. Aquaculture International 11: 183-194.

Geffen AJ, CJ Fox \& RD Mash. 2006. Temperature-dependent development rates of cod Gadus morhua eggs. Journal of Fish Biology 69: 1060-1080.

Gracia-López V, M Kiewek-Martínez, M MaldonadoGarcía. 2004. Effects of temperature and salinity on artificially reproduced eggs and larvae of the leopard grouper Mycteroperca rosacea. Aquaculture 237: 485-498.

Hennea JP \& WO Watanabe.2003. Effects of light intensity and salinity on growth, survival, and whole-body osmolality of larval southern flounder Paralichthys lethostigma. Journal of the World Aquaculture Society 34(4): 450-465.

Jian CY, SJ Chen \& JC Chen. 2003. Temperature and salinity tolerances of yellowfin sea bream, Acanthopagrus latus at different salinity and temperature levels. Aquaculture Research 34: 175-185.

Jordaan A, SE Hayhurst \& LJ Kling. 2006. The influence of temperature on the stage at hatch of laboratory reared Gadus morhua and implications for comparisons of length and morphology. Journal of Fish Biology 68: 7-24.

Kanazawa A. 1991. Pufferfish, Fugu rubripes. In: Wilson RP (ed). Handbook of nutrient requirements of finfish, pp. 123-129. CRC Press, Boca Raton. 
Komar C, JF Turnbullb, A Roque, E Fajer \& NJ Duncan. 2004. Effect of water treatment and aeration on the percentage hatch of demersal, adhesive eggs of the bullseye puffer (Sphoeroides annulatus). Aquaculture 229: 147-158.

Kucera CJ, CK Faulk \& GJ Holt. 2002. The effect of parental acclimation to spawning salinity on the survival of larval Cynoscion nebulosus. Journal of Fish Biology 61: 726-738.

Ottesen O \& S Bolla. 1998. Combined effects of temperature and salinity on development and survival Atlantic halibut larvae. Aquaculture International 6: 103-120

Petereit C, H Haslob, G Kraus \& C Clemmesen. 2008. The influence of temperature on the development of Baltic Sea sprat (Sprattus sprattus) eggs and yolk sac larvae. Marine Biology 154: 295-306.

Radoniæ M, AV López, M Oka \& EO Aristizábal. 2005. Effect of the incubation temperature on the embryonic development and hatching time of eggs of the red porgy Pagrus pagrus (Linne, 1758) (Pisces: Sparidae). Revista de Biología Marina y Oceanografía 40(2): 91-99.

Rodríguez-Ibarra LE, MI Abdo-de la Parra, G Velasco-Blanco, N García-Aguilar \& LS Álvarez-Lajonchère. 2010. Evaluación de métodos para eliminar la capa adherente de los huevos de botete diana Sphoeroides annulatus (Jenyns). Revista de Biología Marina y Oceanografía 45(1): 147-151.

Rodríguez-Ibarra LE, MI Abdo-de la Parra, GA RodríguezMontes de Oca, CY Padilla-Aguiar, VY ZepedaMercado, G Velasco-Blanco \& N García-Aguilar. 2011. Efecto de la acriflavina, formalina y glutaraldehído sobre la desinfección y la eclosión de los huevos del botete diana Sphoeroides annulatus. Revista de Biología Marina y Oceanografía 46(1): 59-65.

Rutaisire JA \& J Booth. 2004. Induced ovulation, spawning, egg incubation, and hatching of the Cyprinid fish Labeo victorianus in Captivity. Journal of the World Aquaculture Society 35(3): 383-391.
Sánchez-Cárdenas R, BP Ceballos-Vázquez, M ArellanoMartínez, MC Valdez-Pineda \& RE Morán-Angulo. 2007. Reproductive aspects of Sphoeroides annulatus (Jenyns, 1842) (Tetraodontiformes, Tetraodontidae) inhabiting the Mazatlan coast, Sinaloa, Mexico. Revista de Biología Marina y Oceanografía 42(3): 385-392.

Shi YH, GY Zhang, YZ Zhu, JZ Liu \& WL Zang. 2010. Effects of temperature on fertilized eggs and larvae oftawny puffer Takifugu flavidus. Aquaculture Research 41: 17411747.

Smith TIJ, MR Denson, LD Heyward, WE Jenkins \& LM Carter. 1999. Salinity effects on early life stages of southern flounder Paralichthvs lethostigma. Journal of the World Aquaculture Society 30(2): 236-244.

Stickney RR. 2000. Temperature. En: Stickney RR (ed). Encyclopedia of aquaculture, pp. 929-934. John Willey \& Sons, New York.

Thompson DA, LT Findley \& AN Kerstitch. 1987. Reef fishes of the Sea of Cortez. The rocky-shore fishes of the Gulf of California, 301 pp. The Arizona University Press, Tucson.

Tucker JW. 1998. Marine fish culture, 750 pp. Kluwer Academic Publishers, Boston

Yang Z \& Y Chen. 2005. Effect of temperature on incubation period and hatching success of obscure puffer Takifugu obscurus (Abe) eggs. Aquaculture 246: 173-179.

Zar JH. 1996. Biostatistical analysis, 662 pp. Prentice-Hall, Englewood Cliffs.

Zhang G, Y Shi, Y Zhu, J Liu \& W Zang. 2010. Effects of salinity on embryos and larvae of tawny puffer Takifugu flavidus. Aquaculture 302: 71-75.

Recibido el 24 de junio de 2011 y aceptado el 16 de diciembre de 2011 